grafting. J Thorac Cardiovasc Surg. March 1, 2013 [Epub ahead of print].

2. Kottenberg E, Thielmann M, Bergmann L, Heine T, Jakob H, Heusch G, et al. Protection by remote ischemic preconditioning during coronary artery bypass graft surgery with isoflurane but not propofol: a clinical trial. Acta Anaesthesiol Scand. 2012; 56:30-8.

3. Heusch G, Musiolik J, Kottenberg E, Peters J, Jakob H, Thielmann M. STAT5 activation and cardioprotection by remote ischemic preconditioning in humans: short communication. Circ Res. 2012 110:111-5.

4. Zhou C, Yao Y, Zheng Z, Gong J, Wang W, Hu S, et al. Stenting technique, gender, and age are associated with cardioprotection by ischaemic postconditioning in primary coronary intervention: a systematic review of 10 randomized trials. Eur Heart J. 2012;33:3070-7.

5. Heusch G. Cardioprotection: chances and challenges of its translation to the clinic. Lancet. 2013;381:166-75.

6. Peters J. Remote ischaemic preconditioning of the heart: remote questions, remote importance, or remote preconditions? Basic Res Cardiol. 2011; 106:507-9.

http://dx.doi.org/10.1016/

j.jtcvs.2013.04.034

\section{AVOIDING TRACHEOSTOMY COMPLICATION}

To the Editor:

I enjoyed the recent article, “"Corkscrew stenosis': Defining and preventing a complication of percutaneous dilatational tracheostomy," by Jacobs and colleagues ${ }^{1}$ in the February issue of The Journal of Thoracic and Cardiovascular Surgery.

We have performed percutaneous tracheostomy for longer than 10 years at our Medical Center. We have not seen an increase in postpercutaneous tracheal stenosis, and have not performed a tracheal resection for this complication. When performing percutaneous tracheostomy, we attempt to place the tracheostomy lower on the anterior wall of the trachea (ie, just below the thyroid isthmus) to avoid the isthmus and subsequent bleeding into the tracheobronchial tree.

If the tracheostomy with dilator does not pass easily into the trachea, we dissect the subcutaneous tissue and/or dilate the tracheal opening with a standard tracheal dilator or clamp. These steps usually allow easy passage of the tracheostomy.

We instruct our bronchoscopist, usually the anesthesiologist, to pull back the endotracheal tube so that we enter the trachea without impaling the endotracheal tube. Under these circumstances, the endotracheal tube is just proximal in the airway to where the tracheostomy is being inserted. When the endotracheal tube is positioned just proximal to the tracheostomy insertion site, anterior tracheal ring fracture is prevented (as described by the authors).

We agree with the authors that the positioning of the supportive endotracheal tube is important in preventing anterior tracheal ring fracture. We also believe that placing the tracheostomy just inferior to the thyroid isthmus, which may serve as a cushion for the anterior tracheal ring, and dilating the skin incision or tracheal opening itself have prevented us from experiencing this complication.

Frank A. Baciewicz, Jr, MD Department of Cardiothoracic Surgery

Wayne State University School of Medicine Detroit, Mich

\section{Reference}

1. Jacobs JV, Hill DA, Petersen SR, Bremner RM, Sue RD, Smith MA. "Corkscrew stenosis": defining and preventing a complication of percutaneous dilatational tracheostomy. J Thorac Cardiovasc Surg. 2013;145:716-20.

$$
\text { http://dx.doi.org/10.1016/ }
$$$$
\text { j.jtcvs.2013.03.042 }
$$

\section{Reply to the Editor:}

We greatly appreciated the thoughtful review of our article provided by Dr Baciewicz. Furthermore, the suggestions offered by Dr Baciewicz are of great interest and work well at his center, where he has not seen "corkscrew" tracheal stenosis after percutaneous dilatational tracheostomy (PDT) in the same way that we have been receiving them at our referral center.

We agree that adequate dissection of soft tissue anterior to the trachea is critical in avoiding excessive force and torque when advancing the dilator, which can lead to tracheal ring fractures, as described. Because this is a minimally invasive means of providing a tracheostomy, there is often a tendency to make the skin incision as small as possible. This should be avoided. An incision large enough to accommodate the dilator and then the tracheostomy without great resistance should be made (at least 1.5-2 $\mathrm{cm})$. Furthermore, using a clamp to dissect and spread the soft tissue anterior to the trachea is similarly important and done routinely at our institution.

Dr Baciewicz also describes dilating the actual trachea with a tracheal dilator or clamp when there is difficulty passing the tracheostomy with the dilator. This was first described during the percutaneous technique by Griggs and colleagues ${ }^{1}$ in 1990 using guidewire dilating forceps. Since then, this technique has been compared with the single-step curved dilator technique in multiple small randomized studies, most of which found the 2 techniques similar. ${ }^{2-4}$ We use the Griggs technique in a few of our cases $(3 \%)$ when we encounter a trachea that is particularly difficult to dilate. These tenacious tracheas are most often encountered in young patients, and we agree that the Griggs technique is an important maneuver that should be in the armamentarium of those performing PDTs.

We appreciate the comments provided regarding the location of placement along the trachea. Dr Baciewicz recommends placing the tracheostomy lower along the anterior tracheal wall just inferior to the thyroid isthmus. We agree with the "low" placement of the tracheostomy to a certain extent. The tracheostomy placement should be low enough that it does not risk injuring the cricoid 